\title{
Study of the stress oscillation phenomenon in syndiotactic polypropylene/montmorillonite nanocomposites
}

\author{
D. E. Mouzakis* \\ Technological Educational Institute of Larisa, Department of Mechanical Engineering, A.T.E.I of Larisa, GR-411 10, \\ Larisa, Hellas (Greece)
}

Received 5 October 2009; accepted in revised form 17 February 2010

\begin{abstract}
The phenomenon of Stress Oscillation (SO) was studied in syndiotactic polypropylene and syndiotactic polypropylene nanocomposites with montmorillonite. The effect was provoked by varying the crosshead speed during tensile testing of thin stripes. The internal morphology of the stress oscillated specimens was studied by scanning electron microscopy on chemically etched samples revealing that cavitation prevails inside the opaque stripes of the yielded areas. Differential scanning calorimetry proved that there exists virtually no crystallinity differentiation between the characteristic alternating opaque/transparent stripes that mark the stress oscillation during necking. Finally a simple finite element model of the necking area of the specimens revealed non-uniform internal stress distributions of yield-point magnitudes.
\end{abstract}

Keywords: nanocomposites, polymers, stress oscillation, syndiotactic polypropylene, material testing

\section{Introduction}

The stress oscillation phenomenon, which occurs at the phase of cold drawing of tensile specimens during testing, was observed in 1924 for the first time, for thin metal sheet, deformed at low temperatures [1]. Stress oscillation (SO) is usually observed during the stable propagation of the neck in polymers under tensile loading. The phenomenon begins with a sudden fluctuation of the normally constant or slightly rising necking stress, resulting in a periodic stress-strain variation. This stress fluctuation is accompanied by the appearance of alternating transparent/opaque zones in the necking area of the specimen [2]. The stress oscillation effect can appear either during semi-static [2] or tensile impact loading [3-5], spontaneously [2-4] or provoked [6], by an abrupt change in the specimen loading speed. It can be observed for both amorphous and semi-crystalline polymers too. Amorphous but crystallisable polymers like poly(ethyl- ene terephtalate) also exhibit this effect [7]. Moreover, it was also observed in amorphous non-crystallizable polymers like polycarbonate (PC) [6]. Quite a lot of effort has been invested by different researchers, employing different approaches to interpret this phenomenon. However the exact mechanism behind this phenomenon remains elusive. Adrianova et al. [8] has suggested that the formation of the alternating opaque/transparent zones is related to differential heat diffusion. Temperature at the necking region tends to fluctuate, because of the polymer poor heat conductivity and this causes a reduction in the local elastic modulus of the material, triggering thus stress oscillation. One of the most plausible explanations was proposed by Karger-Kocsis et al. [3]. He proposed that a combined effect of crystallization due to cold drawing of the polymer in the necking region accompanied by heat dissipation due to plastic flow leads to a 'stick/slip' mechanism of plastic deformation 
which results in the appearance of the alternating zones. The same author proposed that in syndiotactic polypropylene (sPP) samples [2] a local elastoplastic deformation network is being created, characterized by trans-planar crystallized segments. These segments cause a strain-hardening effect during the material necking which leads to stress fluctuation. Gatos et al. [9] have successfully shown that the result of the stress oscillation in $\mathrm{SPP}$ is a differentiating crystallization scheme in the opaque and the transparent zones of the specimens. According to Bazhenov et al. [10,11], pores which are created in the plastic deformation region and polymer heat conductivity are the main factors influencing the mechanism of stress oscillation. Toda et al. [12] have worked on a variety of polymers with regard to stress oscillation. They utilized Barenblatt's thermomechanical model [13] and by using an infrared camera they observed that during the necking of polymers local temperature can overshoot the glass transition temperature. In this way they have concluded that local temperature peaks can lead to local enhancements in the polymer crystallinity which could result in strain hardening and therefore stress oscillation phenomena. Recently, Ronkay and Czigány [14] recognized the existence of cavitational yielding within the stress oscillated area of specimens. They proposed that micro-voids form in the presence of shear stresses acting in the area where the neck propagates in the bulk polymer. However the exact mechanism of microvoid formation has not been clarified yet.

This work focuses on the stress oscillation phenomenon as it was observed for specimens manufactured by hot pressing of sPP and its nanocomposites with montmorillonite. The stress oscillation phenomenon was provoked by alterations of the crosshead speed. Stress oscillated areas of these specimens where studied by means of differential scanning calorimetry and scanning electron microscopy in order to reveal valuable evidence on the stress oscillation mechanism. Finite element modeling of the necking area of the specimens helped simulate the stress fields acting in the area where the stress oscillation takes place.

\section{Materials and methods}

Syndiotactic polypropylene (sPP) of high purity $\left(M_{w}=135000 \mathrm{~g} / \mathrm{mol}\right.$, tacticity $\left.68 \%\right)$ from Fina Oil and Chemical Co. (USA) was used in this study. Nanocomposite films were manufactured by melt mixing of an organically modified (quaternary ammonium salt) montmorillonite (Cloisite ${ }^{\circledR} 20 \mathrm{~A}$, Southern Clay, Inc, USA) with the polymer matrix and subsequent hot pressing. sPP and nanoclay were mechanically mixed for $3 \mathrm{~min}$ prior to a $3 \mathrm{~min}$ melting phase at $170^{\circ} \mathrm{C}$. The final melt mixing took 3 more minutes. Afterwards, the mixture was hotpressed at $170^{\circ} \mathrm{C}$ with a pressure of $20 \mathrm{bar}$ for ca. $10 \mathrm{~min}$ and was finally quenched at $0^{\circ} \mathrm{C}$. Thin films $(200 \mu \mathrm{m})$ of sPP nanocomposites with several compositions of montmorillonite, $0,0.5,1,2,3$ and $4 \mathrm{wt} \%$ were produced in this way. Prior to testing all specimens were isothermally annealed at $80^{\circ} \mathrm{C}$ for $20 \mathrm{~min}$ to ensure high crystallinity which favors stress oscillation in sPP [15].

Specimens of both pure sPP and its nanocomposites with montmorillonite in the form of rectangular stripes of $80 \times 7.5 \times 0.34 \mathrm{~mm}^{3}$, were cut from pressmolded sheet for tensile testing. Tensile tests were performed on a Hounsfield HK20-W (Tinius Olsen, Surrey, England) desktop machine. Force-elongation curves were digitally recorded for further processing. During tensile testing, the crosshead speed was varied by the operator in order to trigger the stress-oscillation effect. Crosshead speeds used were: $5 \mathrm{~mm} / \mathrm{min}$ in order to produce a well pronounced necked area of the polymer and consequently speed was varied from 20 to $40 \mathrm{~mm} / \mathrm{min}$ in order to trigger the initiation of stress oscillation effect.

Differential Scanning Calorimetry (DSC) experiments were conducted in a DSC Q100 (TA Instruments, New Castle, Delaware, USA) system. Samples were cut from the a) undeformed, b) white/ opaque and c) transparent zones of the tensile specimens with respect to Figure 1, in order to establish changes in the crystallization behavior due to the

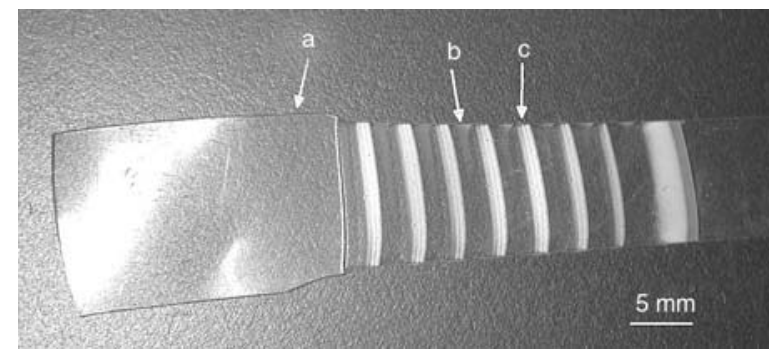

Figure 1. Optical photography of a sPP tensile specimen after stress oscillation: a) unstretched area, b) transparent zone $\kappa \alpha l, c)$ opaque zone 
stress/oscillation effect. Specimen heat/cool rate was $10^{\circ} \mathrm{C}$ and a heat $/ \mathrm{cool} /$ heat scheme was applied to all specimens. Three repetitions were run for each different specimen. Specimen crystallinity was calculated from Equation (1) where $\Delta H_{m}^{0}=$ $190.4 \mathrm{~J} / \mathrm{g}$ is the well known heat of fusion of sPP crystals [6] (Equation (1)):

$x=\frac{\Delta H_{m}-\Delta H_{c}}{\Delta H_{m}^{0}}=\frac{\Delta H_{m}-\Delta H_{c}}{190}$

where, $x$ is the \% of crystallinity, $\Delta H_{m}$ and $\Delta H_{c}$, melt and crystallization enthalpies respectively.

In order to study the internal structure of the necked area of the stress oscillated specimens samples were studied by a LEO SUPRA 35VP Field Emission (Carl Zeiss AG, Jena, Germany and a JEOL (Jeol Ltd, Tokyo, Japan) Scanning Electron Microscope. Some samples were selectively etched for 2 hours by using a $60 / 40 \mathrm{wt} \%$ acidic mixture of $\mathrm{H}_{2} \mathrm{SO}_{4} / \mathrm{HNO}_{3}$ to which $2 \mathrm{wt} \%$ of $\mathrm{KMnO}_{4}$ was added. Prior to SEM examination, specimens where covered with a layer of $20 \mathrm{~nm} \mathrm{Au}$ in a BALZERS SCD 050 (Leica Microsystems, Liechtenstein) sputtering device.

\section{Results and discussion}

In Figure 1, the digital picture of the stress oscillated area of a sPP tensile specimen is shown. The specimen exhibits the typical characteristic specifications of such specimens: alternating opaque and transparent stripes. Figure 2 shows the load-displacement curve of that specimen. Initially, the specimen was subjected to a $5 \mathrm{~mm} / \mathrm{min}$ crosshead speed and it has yielded in a normal mode as shown in this figure. Subsequently, the crosshead speed

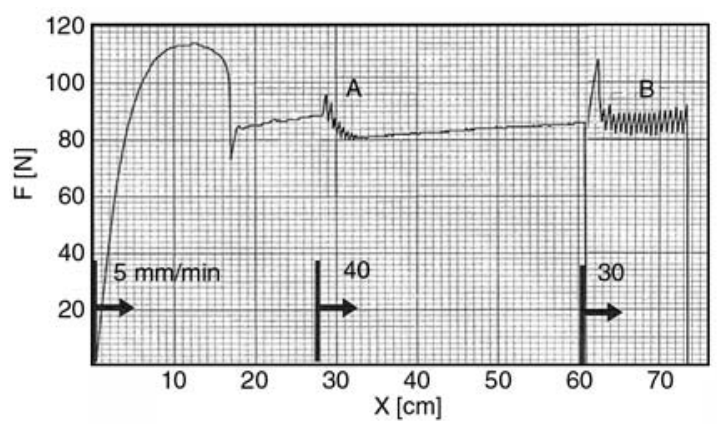

Figure 2. Stress oscillation scheme under crosshead speed variations in a SPP specimen: Region A: Crosshead speed switching from 5 to $40 \mathrm{~mm} / \mathrm{min}$, Region B: Crosshead speed switching from 40 to $30 \mathrm{~mm} / \mathrm{min}$ was changed to $40 \mathrm{~mm} / \mathrm{min}$ causing an unstable stress oscillation event which soon attenuated (point $A$ of the diagram). A few moments later, the crosshead speed was altered again to $30 \mathrm{~mm} / \mathrm{min}$ (point $B$ of the diagram) and this change triggered a smooth stress oscillation effect up to specimen rupture. Stripes in Figure 1 correspond to the latter phase $B$ of the force-elongation curve of Figure 2 . In both areas $A$ and $B$ where tensile speed was changed, it is evident that force rises to a maximum (strain hardening) prior to the initiation of stress oscillation. This strain hardening effect leading to stress oscillation is probably the key to understanding this phenomenon. It should be mentioned here, that only the $0.5 \mathrm{wt} \%$ in montmorillonite nanocomposite with sPP matrix, produced stress oscillations when subjected to the change of tensile speed. The force-elongation curve of such a specimen is shown in Figure 3. The stress oscillation for that specimen was provoked by initially starting at a crosshead speed of $20 \mathrm{~mm} / \mathrm{min}$ and by sudden increase at $30 \mathrm{mmm} / \mathrm{min}$. The stress oscillation here denoted by arrows in Figure 3 was unstable, with alternating force superimposed on typical strain hardening as seen in Figure 3. So, if more strain hardening can appear during plastic deformation then it must be localized in the oscillating area. All other concentrations, namely $1,2,3$, and $4 \mathrm{wt} \%$ in montmorillonite yielded a typical force-elongation behavior of ductile polymers without any stress oscillation characteristics. In conclusion, the stress oscillation phenomenon from a yielding mechanism point of view appears to be an alternating procedure between strain hardening and plastic flow of the

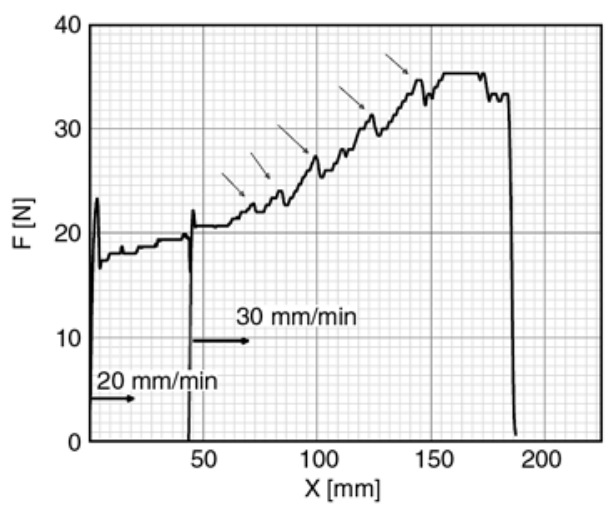

Figure 3. Stress oscillation scheme under crosshead speed variations in a nanocomposite $\mathrm{sPP}+0.5 \mathrm{wt} \%$ Cloisite 20A specimen. Arrows mark unstable oscillation peaks 
necking area of the specimen as Karger-Kocsis has already suggested [5].

\subsection{Crystallization behavior of the stress oscillation bands}

Figure 4 presents the thermal behavior (heat flux) during the heating phase of the pure sPP specimen stress oscillated areas. Both the opaque and transparent stripes appear to have the same thermal response. Pure sPP shows a small endothermic peak at $100^{\circ} \mathrm{C}$, which owes its existences to helical form I crystalline phase [6,9]. In both opaque and transparent zones this peak is being suppressed as seen in Figure 3. This can be attributed the partial transformation of helical I to the trans-planar III conformation due to mechanical drawing of the polymer $[6,9]$.

Figure 5 shows the typical thermal behavior during heating of the $0.5 \mathrm{wt} \%$ montmorillonite nanocomposite stress oscillated samples. A small endothermic lump can be observed in all cases for these specimens at ca. $50^{\circ} \mathrm{C}$ which is typical for the partial melting of the unstable trans-planar III conformation [9] of the sPP matrix. A well pronounced helical I phase melting at $100^{\circ} \mathrm{C}$ is seen for the unstretched samples. This peak is being suppressed by cold drawing during the neck extension procedure.

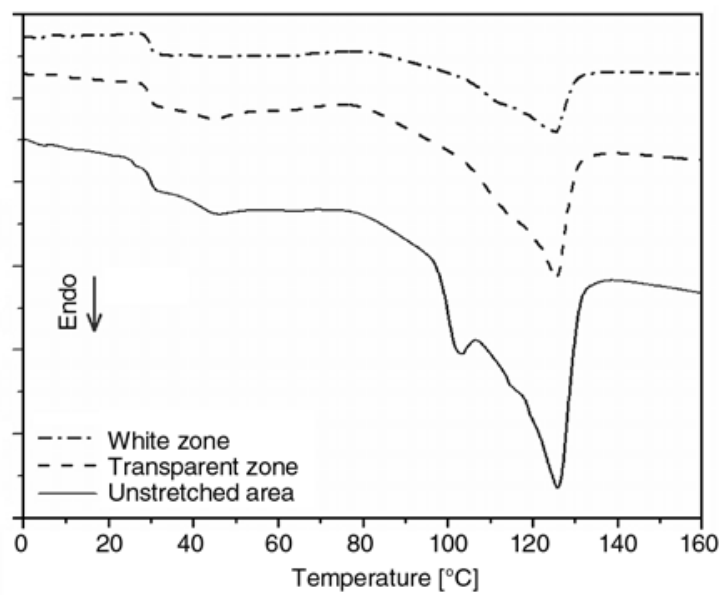

Figure 4. Differential Scanning Calorimetry during heating of sPP stress oscillated specimens

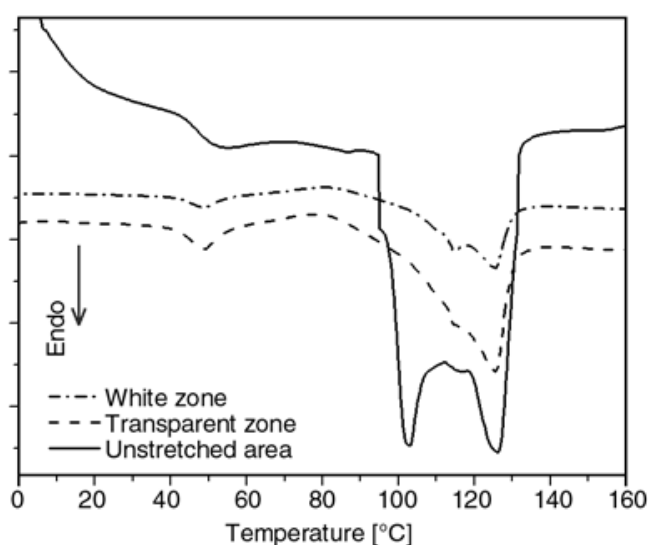

Figure 5. Differential Scanning Calorimetry during heating of a sPP $+0.5 \%$ Cloisite $20 \mathrm{~A}$ stress oscillated nanocomposite specimen

It is easy to conclude from Figure 5 that the thermal response of the opaque and transparent zones does not differentiate as observed for the pure sPP samples.

In Table 1 the results from the DSC experiments are summarized. There appears no significant impact of stress oscillation on the melting temperature of pure sPP. Also the overall crystallinity was calculated by Equation (1) of the opaque and transparent samples remains almost the same, whereas the unstretched samples yielded a little lower data. This implies that the effect of stress oscillation is a small rise due to orientation (cold drawing) in the material crystallinity. This has been also verified by García Gutiérrez et al. [15] by means of synchrotron- $\mu$ SAXS who found no significant change in the crystallinity degree between opaque and transparent zones but only in the conformational order of the polymer. The corresponding crystallinity results for the $0.5 \mathrm{wt} \%$ montmorillonite nanocomposites are also shown in Table 1. Again, the results of the opaque and transparent zones exhibit the same amount of crystallization. Interestingly, the crystallinity of the nanocomposite-unstretched samples is almost $400 \%$ higher than the stress oscillated areas. Probably, this is the effect of the montmorillonite [16], which favours the crystal-

Table 1. DSC Crystallinity results for the pure sPP and sPP+0.5 wt $\%$ modified nanoclay content samples from stress oscillation tensile experiments

\begin{tabular}{|l|c|c|c|c|c|c|}
\hline \multirow{2}{*}{} & \multicolumn{3}{|c|}{ Pure sPP } & \multicolumn{2}{c|}{ sPP+0.5 wt\% Cl.20A } \\
\cline { 2 - 6 } & $\begin{array}{c}\text { Opaque } \\
\text { zones }\end{array}$ & $\begin{array}{c}\text { Transparent } \\
\text { zones }\end{array}$ & $\begin{array}{c}\text { Unstretched } \\
\text { area }\end{array}$ & $\begin{array}{c}\text { Opaque } \\
\text { zones }\end{array}$ & $\begin{array}{c}\text { Transparent } \\
\text { zones }\end{array}$ & $\begin{array}{c}\text { Unstretched } \\
\text { area }\end{array}$ \\
\hline$T_{m}\left[{ }^{\circ} \mathrm{C}\right]$ & $125.6 \pm 0.2$ & $125.6 \pm 0.3$ & $126.8 \pm 0.2$ & $125.6 \pm 0.7$ & $125.6 \pm 0.5$ & $126.6 \pm 1.1$ \\
\hline$\Delta H_{m}[\mathrm{~J} / \mathrm{g}]$ & $50.9 \pm 0.2$ & $49.2 \pm 0.9$ & $45.3 \pm 0.9$ & $9.2 \pm 0.5$ & $10.3 \pm 0.2$ & $39.8 \pm 1.0$ \\
\hline Crystallinity $[\%]$ & $26.7 \pm 0.1$ & $25.8 \pm 0.5$ & $23.6 \pm 1.5$ & $4.8 \pm 1.1$ & $5.3 \pm 0.4$ & $20.9 \pm 0.5$ \\
\hline
\end{tabular}


lization of helical form I of sPP $[9,16]$ during the isothermal crystallization phase. However, as seen from Figure 5 these conformations tend to vanish when mechanical stress is imposed. Probably, the mechanically re-oriented macromolecules lose their preferential form I conformation under mechanical loading.

\subsection{Internal morphology and structure}

SEM pictures assisted in determining the internal structure of the stress oscillated specimens. Between nanocomposites and pure sPP samples, no difference in the structure was observed, so the internal morphology of the latter is being discussed here. Figure 6, shows both the fracture surface and the edge-on side view of a stress oscillated sPP tensile specimen; many interesting observations can be made on the topography of the specimen. Firstly, the outer surface of the sample in Figure 6a shows an undulation pattern. Also, the fracture surface of the specimen which was separated exactly at the beginning of an opaque zone shows a distinct difference between the outer layers and internal core structure, as presented in the frame of Figure $6 \mathrm{~b}$. The outer skins of the oscillation zone surround an elliptical zone of different morphology, i.e. a skin-core structure is made visible. So, an important conclusion can be drawn here: stress oscillation phenomenon does not appear uniformly, not only in an optical manner, showing opaque and transparent zones but also exhibits non-uniformity across the specimens' thickness. However, it is rather unlikely that this shall produce differences in crystallinity, since the outer layer is common to both opaque and transparent zones. It is the core which produces the difference if any, due to cavitation procedure [14]. This finding required a deeper insight, so it was decided that some samples should
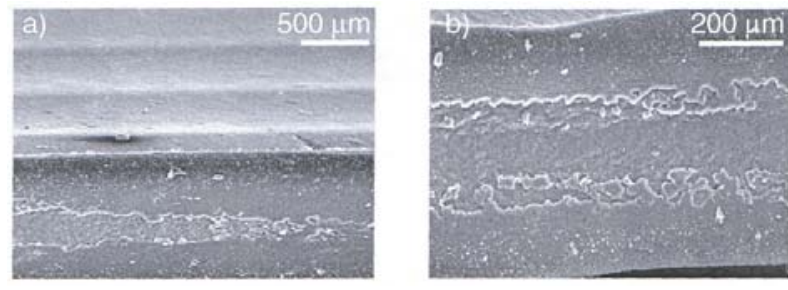

Figure 6. SEM microphotographs (fracture surface) of a stress oscillated sPP specimen which shows surface undulations (a) and skin-core cross-sectional morphology (b)

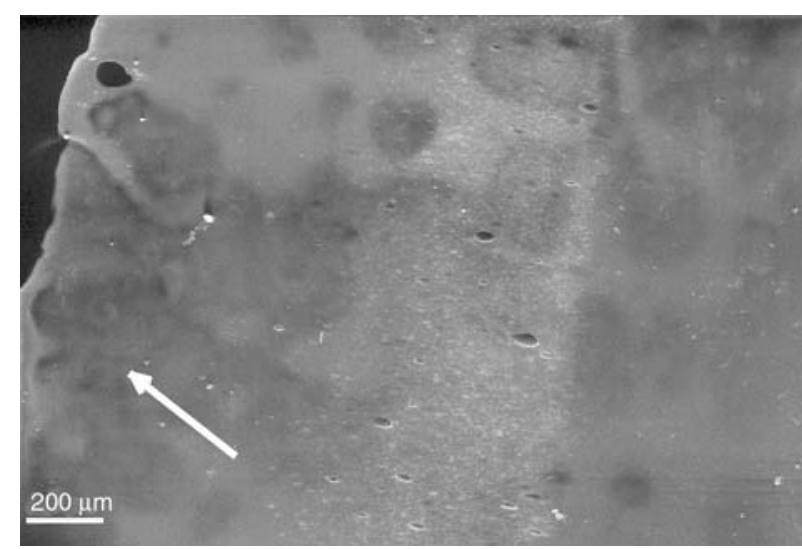

Figure 7. SEM microphotography of a stress oscillated sPP specimen after chemical etching. Arrow shows direction of tensile loading.

be chemically etched in order to remove the outer skin layers, in order to reveal the inner structure.

Up to this moment, researchers which have studied the internal morphology of the cross-section of stress oscillated tensile specimens proved the cavitational yielding mode of the white zones [14]. Therefore, some specimens where etched chemically as shown in parallel to the tensile direction. Figure 7 presents the top view aspect of a sPP tensile specimen as seen in the SEM after the chemical etching procedure has taken place. The white arrow on the left indicates the direction to which the tensile load was applied. A distinct bright grey zone can be seen in the middle of the specimen surrounded by two darker ones. This zone corresponds to one of the white zones of the specimen surrounded by the transparent ones. At this far field view, some cavities can be observed inside and in the vicinity of the white zone. So, the bright area corresponds to a white zone, being brighter to SEM

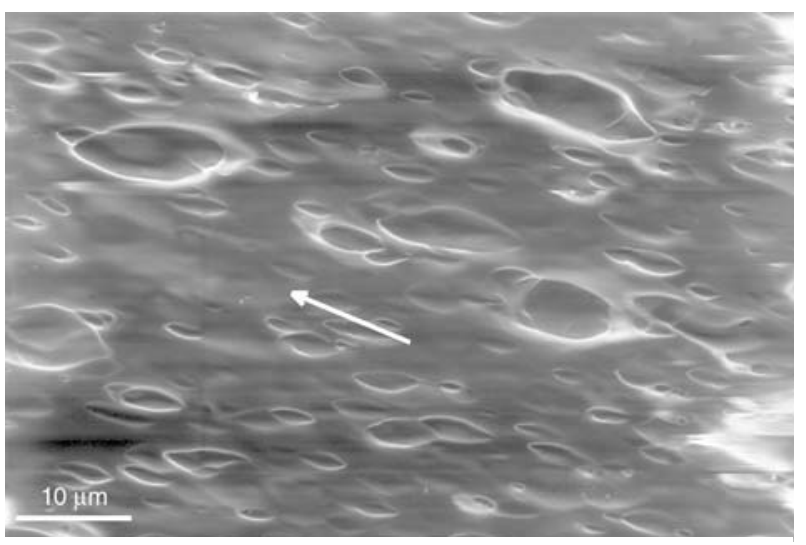

Figure 8. SEM microphotograph of the opaque (white) zone of a sPP tensile specimen. Arrow shows direction of tensile loading 
because more electrons are reflected from cavity edges. As seen in Figure 8, which shows a part of the white zone of Figure 7 in higher magnification, the white zone is dominated by cavitational yielding. In other words, stress oscillation appears to invoke a secondary yielding mechanism during plastic flow (yielding) of the neck: cavitation. SEM frames of Figures 7 and 8 show larger and smaller cavities which are of elliptical shape. The arrows mark the tensile strain direction. It is most probable, that the elliptical shape of the cavities owes to tensile strain, since the main axes of these ellipses and tensile axis are the same as shown in that picture. On the other hand, it has been confirmed by numerous workers [17] that cavitational yielding is one of the major mechanisms of stress whitening in polymers and polymer matrix composites. So, perhaps the reason behind the formation of the opaque zones is a type of overstressing of the necking area of the specimen. Polymer cavitates in order to provide a relaxation mechanism to $3 \mathrm{D}$ stress fields acting in that area. Once the stresses have been accommodated and the excess elastic energy is dissipated into heat through cavitational yielding, the polymer returns into normal plastic flow forming a transparent zone. Further: strain hardening leads into overstressing again and once more another opaque zone forms by cavitation. This cycle is repeated many times until specimen fails or the phenomenon stops. The above scenario based on our SEM findings however, demands some theoretical modeling of the stress fields acting in the necking area of the tensile specimen by analytical or arithmetic techniques.

On the left, side of the white zone of Figure 7 the borderline between opaque and transparent zone appears to be more diffuse, whereas on the left the two areas are more distinctively separated. There appears to be an area in which there is a transition from the opaque to the transparent zone and vice versa. In every white (opaque) zone of the specimen one side is diffuse and the other is clearly separated from the adjacent transparent one. In order to confirm this finding, another different stress oscillated tensile specimen area was etched and examined in the JEOL 5400 SEM. This is the view given in the corresponding Figure 9. The area of transition (diffuse cavitation) is on the right side of the specimen, whereas on the left of the white-cavitated zone the separation between transparent zone

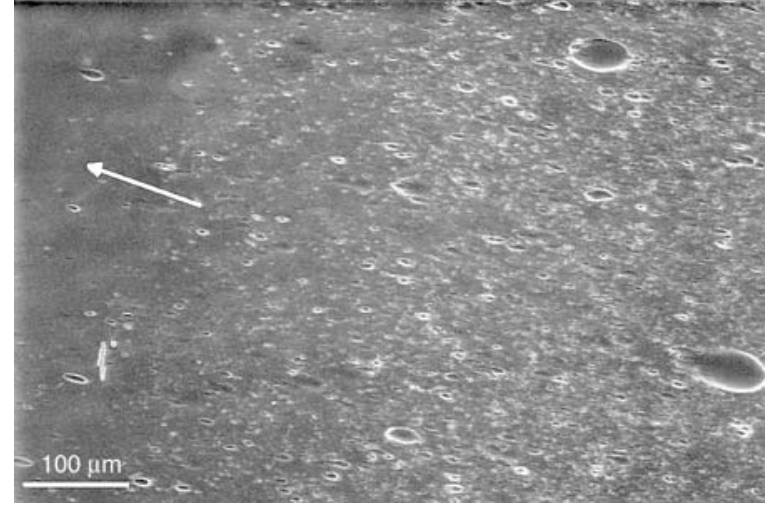

Figure 9. SEM microphotography of the transitional area (opaque to transparent) of a stress oscillated tensile specimen of $\mathrm{SPP}$

and opaque is unmistakable. So our finding is confirmed: in some stage of the stress oscillation procedure a transitional area between opaque and transparent areas is being formed. The authors could not detect evidence whereas this transitional area forms when a transparent zone gives its place to an opaque one, or vice-versa.

\subsection{Finite Element Modelling}

In order to obtain some idea on the stress field acting during loading of a necked sPP specimen, a rough model was constructed and solved by employing ANSYS v.11 software (licensed to T.E.I. of Larisa). As shown in Figure 10, wedgetype geometry was chosen to represent the transitional area from necked/yielded to non-yielded specimen. The model was solved for half of the specimen due to symmetry. Of course this model was quasi-static and meant only to obtain some idea of the stress fields in necked sPP specimens; the ideal solution would be a dynamic model, but this is very difficult to perform due to the stress oscillation phenomenon. Due to the anisotropy of the stress fields expected here, owing to both the

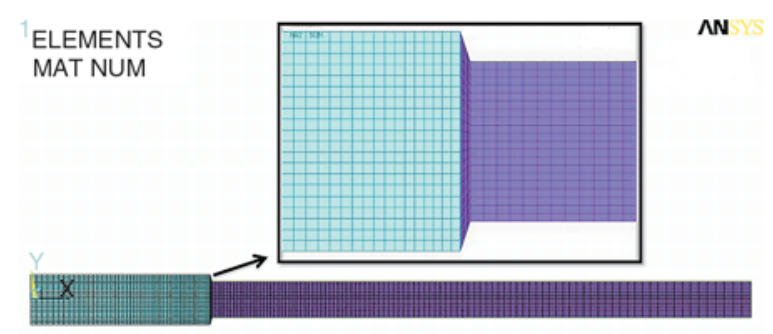

Figure 10. Finite Element Model of the dumbbell specimen of s-PP. Inset view shows the necking area in magnification. 


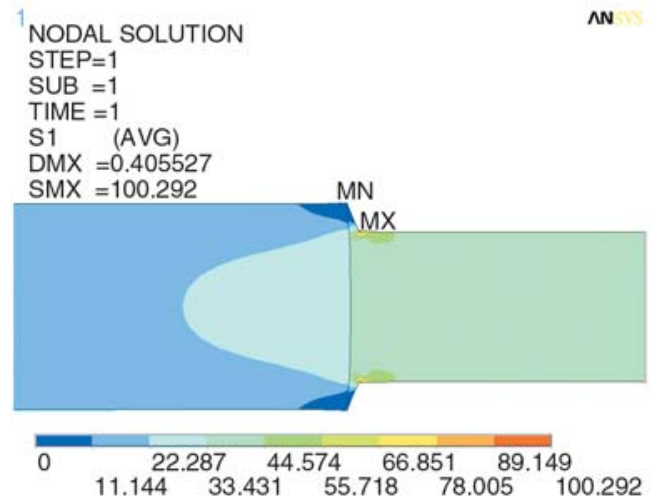

Figure 11. Principal stress results ( $x$-direction) in the necking area of a tensile specimen of s-PP as calculated by FEM

geometry and the properties of the yielded/nonyielded areas of the specimen, principal stresses across the $x$-direction are depicted.

As seen in the contour plot of Figure 11 anisotropy in the distribution of stresses around the necked area is evident. Moreover, overstressing of the nonyielded area above the sPP yield point (ca. $20 \mathrm{MPa}$ ) is also observed (hyperbolic stress field left of the necked area). Also, some points of high stresses can be seen where the end of the wedge type region meets the necked specimen, but this is only due to the wedge steep angle. From the above analysis, though simplistic, an important conclusion can be drawn: In the non-yielded/non necked area of the sPP specimens, non uniform stress fields act, imposing stresses higher or in the magnitude of the yield point. Naturally, that finding requires further detailed modeling taking into account the exact geometry features of the transitional necking area (i.e. differences in thickness and curvature of the wedge).

\section{Conclusions}

Based on the above discussion on the stress oscillation experimental observations and FEM results following conclusions can be drawn.

- The SO phenomenon was verified to initiate when test speed was altered for both SPP and its nanocomposite with nanoclay.

- The crystallinity within the stress oscillated area does not differentiate between transparent and opaque zones for both pure sPP and nanocomposite.
- The opaque stripes exhibit a skin-core morphology featuring an external skin covering the stress-whitened/cavitated core.

- Finite Element Modeling showed non-uniform overstressing, ahead of the neck propagation area requiring further investigation.

\section{Acknowledgements}

The author is grateful to Mr. Angelos Mintzas of the Department of Engineering Science, University of Oxford, for his kind assistance in the procedure of Finite Elements Modelling. Thanks are also due to Dr V. Gregoriou's team in ICEHT-FORTH, Patras-Greece for providing the materials under study.

\section{References}

[1] Portevin A., Le Chatelier F.: Heat treatment of aluminium-copper alloys. Transactions of the American Society for Steel Treating, 5, 457-478 (1924).

[2] Karger-Kocsis J., Shang P. P.: A modulated DSC study on the stress oscillation phenomenon in a syndiotactic polypropylene. Journal of Thermal Analysis and Calorimetry, 69, 499-507 (2002). DOI: 10.1023/A:1019903605228

[3] Karger-Kocsis J., Benevolenski O. I., Moskala E. J.: Toward understanding the stress oscillation phenomenon in polymers due to tensile impact loading. Journal of Material Science, 36, 3365-3371 (2001). DOI: 10.1023/A:1017935323058

[4] Mouzakis D. E., Karger-Kocsis J.: Effects of gasoline absorption on the tensile impact response of HDPE/ SelarTM laminar microlayer composites. Journal of Applied Polymer Science, 68, 561-569 (1998). DOI: $10.1002 /($ SICI) $1097-4628(19980425) 68: 4<561::$ AID-APP7>3.0.CO;2-K

[5] Karger-Kocsis J., Czigány T., Moskala E. J.: Stress oscillation in amorphous copolyesters due to tensile impact. Polymer Engineering and Science, 39, 1404 1411 (1999). DOI: $10.1002 /$ pen. 11531

[6] Gregoriou V. G., Kandilioti G., Gatos K. G.: An infrared spectroscopic approach to the polymorphic behavior of syndiotactic polypropylene and its crystalcrystal transformation during mechanical stretching. Vibrational Spectroscopy, 34, 47-53 (2004). DOI: $10.1016 /$ j.vibspec.2003.08.004

[7] Ebener H., Pleuger B., Petermann J.: Stress and strain oscillations in syndiotactic polypropylene and in poly(ethylene terephthalate). Journal of Applied Polymer Science, 71, 813-817 (1999). DOI: $10.1002 /($ SICI $) 1097-4628(19990131) 71: 5<813::$ AID-APP15>3.0.CO;2-P 
[8] Andrianova G. P., Kechekyan A. S., Kargin V. A.: Self-oscillation mechanism of necking on extension of polymers. Journal of Polymer Science Part A 2: Polymer Physics, 9, 1919-1933, (1971).

DOI: $10.1002 /$ pol.1971.160091101

[9] Gatos K. G., Kandilioti G., Galiotis C., Gregoriou V. G.: Mechanically and thermally induced chain conformational transformations between helical form I and trans-planar form III in syndiotactic polypropylene using FT-IR and Raman spectroscopic techniques. Polymer, 45, 4453-4464 (2004).

DOI: 10.1016/j.polymer.2004.03.095

[10] Bazhenov S. L., Rodionova Yu. A., Kechek'yan A. S., Rogozinskii A. K.: On the role of thermal conductivity in the formation of self-excited oscillation in poly(ethylene terephthalate). Polymer Science, Series A, 47, 692-699 (2005).

[11] Kechek'yan A. S., Rodionova Yu. A., Bazhenov S. L.: On the role of pore formation in oscillatory neck propagation in poly(ethylene terephthalate). Polymer Science, Series A, 47, 126-133 (2005).

[12] Toda A., Tomita C., Hikosaka M., Hibino Y., Miyaji H., Nonomura C., Suzuki T., Ishihara H.: Thermo mechanical coupling and self-excited oscillation in the neck propagation of PET films. Polymer, 43, 947-951 (2002).

DOI: $\underline{10.1016 / \mathrm{S} 0032-3861(01) 00625-5}$
[13] Barenblatt G. I.: Neck propagation in polymers. Rheologica Acta, 13, 924-933 (1974). DOI: $10.1007 / \mathrm{BF} 01526675$

[14] Ronkay F., Czigány T.: Cavity formation and stressoscillation during the tensile test of injection molded specimens made of PET. Polymer Bulletin, 57, 989 998 (2006).

DOI: $10.1007 / \mathrm{s} 00289-006-0670-8$

[15] García Gutiérrez M. C., Karger-Kocsis J., Riekel C.: Stress oscillation-induced modulated phase transformation and yielding in syndiotactic polypropylene. Chemical Physics Letters, 398, 6-10 (2004). DOI: 10.1016/j.cplett.2004.09.023

[16] Mouzakis D. E., Kandilioti G., Elenis A., Gregoriou V. G.: Ultraviolet radiation induced cold chemi-crystallization in syndiotactic polypropylene clay-nanocomposites. Journal of Macromolecular Science Part A: Pure and Applied Chemistry, 43, 259-267 (2006). DOI: $10.1080 / 10601320500437110$

[17] Karger-Kocsis J., Fakirov S.: Nano- and micromechanics of polymer blends and composites. Hanser, Munich (2009). 